\title{
Effects of a breastfeeding coaching program on growth and neonatal jaundice in late preterm infants in South Korea
}

\author{
Gun Ja Jang ${ }^{1}$, Sangjin Ko ${ }^{2}$ \\ ${ }^{1}$ Professor, Department of Nursing, Daegu University, Daegu; ${ }^{2}$ Assistant Professor, Department of Nursing, University of Ulsan, Ulsan, Korea
}

Purpose: This study examined the effects of a breastfeeding coaching program for mothers on growth and neonatal jaundice in late preterm infants (LPIs). Methods: This was a quasi-experimental study (non-randomized intervention) with a time-series design. The study was conducted among 40 LPIs who were admitted to the neonatal intensive care unit of a university hospital in Daegu, South Korea. In the order of admission, the first 21 infants were assigned to the experimental group, and 19 were assigned to the control group. The intervention program consisted of home- based and web-based practical breastfeeding support education for mothers across a total of 5 sessions. Infant growth was measured using body weight, length, and head circumference, and neonatal jaundice was assessed using transcutaneous bilirubin levels. Results: The likelihood of breastfeeding for infants in the experimental group at 4 weeks after discharge was the same as on the day of discharge, whereas it steadily decreased in the control group. There were significant differences in head circumference between the groups. However, weight, length, and transcutaneous bilirubin levels did not show a significant group-time interaction. Conclusion: A formal breastfeeding coaching program should be considered in clinical settings and at home within the first few weeks postpartum.

Key words: Breast feeding; Coaching; Growth; Neonatal jaundice; Premature infant

\section{Corresponding author \\ Sangjin Ko}

Department of Nursing, University of Ulsan, 93 Daehak-ro, Nam-gu, Ulsan 44610, Korea

TEL: +82-52-259-1298

FAX: +82-52-259-1236

E-MAIL: sangjinko@ulsan.ac.kr

Received Aug 13, 2021

Revised Sep 23, 2021

Accepted Oct 3, 2021

\section{INTRO DUCTION}

In the last decade, the number of births in South Korea has decreased from 470,000 in 2010 to 272,300 in 2020 [1,2]. As a result, Korea's fertility rate of 0.92 in 2019 was lower than the average fertility rate of 1.61 among member countries of the Organization for Economic Cooperation and Development [2]. Conversely, by 2020, the rate of preterm births had grown to $8.5 \%$, reflecting a 1.5 -fold increase compared to the rate in 2010 [2].

Late preterm infants (LPIs) are born between 34 and 36 weeks of gestation, and are physiologically and developmentally immature at birth [3]. Unlike full-term infants, LPIs are at high risk for developing several health issues such as respiratory disease, feeding difficulties, and hyperbilirubinemia in the short term during neonatal hospitalization $[3,4]$. These health problems can result in delays in the initiation of breastfeeding for LPIs. For successful breastfeeding, the Baby-Friendly Hospital Initiative program developed by the United Nations Children's Fund and the World Health Organization suggest hospital policies to encourage breastfeeding and provide maternity services and care for newborns right after delivery [5]. In other words, 3 variables-mothers, newborns, and the hospital environment-are crucial for commencing successful breastfeeding. However, mothers who deliver LPIs are likely to have decreased self-efficacy and increased anxiety associated with breastfeeding [3]. Furthermore, in LPIs, physical and neuronal immaturity can cause poor suck-swallowbreathe coordination, posing unique feeding challenges [6]. In addition, hospital breastfeeding support is less likely to be provided for LPIs than for full-term infants [7]. As a result, LPIs are a vulnerable population when commencing breast- 
feeding and have more breastfeeding-associated health problems [8]. In particular, breastfeeding jaundice, referred to as breast milk jaundice, is characterized by inadequate nutritional intake, caloric deprivation, weight loss, and dehydration [8,9]. The Academy of Breastfeeding Medicine [10] recommends timely lactation support for LPIs in the inpatient and outpatient setting to sustain breastfeeding and prevent neonatal jaundice. Thus, thorough assessment and teaching regarding breastfeeding and ensuring the competence of mothers and LPIs concerning feeding from discharge to several weeks postpartum are essential for the prevention of breastfeeding-associated morbidities [11].

Previous studies have suggested that the relatively high morbidity of LPIs compared to full-term infants is mainly caused by hyperbilirubinemia, which is primarily caused by difficulties with breastfeeding rather than breastfeeding itself [8,12-15]. However, there have been few interventional studies of the effects of breastfeeding education on neonatal jaundice among LPIs.

Infant growth is a primary indicator for assessing infants' nutritional status and health, and it must be evaluated periodically to detect any deviations from corresponding growth standards, as the early years of life are a critical period for growth and development [16]. However, there is no general agreement on how to monitor preterm infant growth or what constitutes ideal infant growth patterns [17]. In particular, one-third of brain development occurs in the final 6 to 8 weeks of gestation, and breastfeeding is essential for LPIs whose brain maturation may be stunted as a result of preterm birth [6]. Thus, breast milk should be provided to LPIs. In a recent integrative study, breastfeeding promotion interventions positively affected the exclusivity and duration of breastfeeding for LPIs [3] but were not associated with significant changes in infant weight or length $[18,19]$. In addition, these studies suggested the need to focus on breastfeeding after LPIs transition to living at home.

Therefore, the purpose of our study was to identify the effects of a breastfeeding coaching program (BCP) for LPIs discharged from the neonatal intensive care unit (NICU) on breastfeeding rates, growth, and neonatal jaundice. We identified some LPIs with neonatal morbidities during the investigation, such as neonatal jaundice, frequent gastrointestinal regurgitation, and inflammation. A follow-up study [19] that examined the effects of the BCP on neonatal morbidities was published earlier than this study. Since the BCP promoted breastfeeding practice in LPIs, this study focused on the effects of the BCP on LPIs' growth and the prevention of neonatal jaundice during the transition to living at home after discharge.

\section{METHODS}

Ethics statement: This study was approved by the Institutional Review Board of Daegu University (No. 1040621-201505-HR-015-02). Informed consent was obtained from the participants.

\section{Study Design}

Our study adopted a non-randomized quasi-experimental design to investigate the effects of the BCP for mothers on growth and neonatal jaundice in their LPIs. We used a time-series design with 5 set measurements on the discharge day and every week for 1 month after discharge.

\section{Setting and Participants}

The participants in this study were 40 LPIs admitted to the NICU at a university hospital in Daegu, Korea, between June 2017 and May 2018. The inclusion criteria were mothers without previous breastfeeding experience who intended to breastfeed and agreed to home visits once a week for 4 weeks after discharge. The exclusion criteria were LPIs who were withheld from feeding for 2 or more days due to health issues or general surgery in the NICU immediately following birth, experienced feeding intolerance for 2 or more consecutive days, or were readmitted to the hospital after being discharged. Mothers received the same breastfeeding education from a lactation specialist before they were discharged from the hospital in both groups. In addition, during the first home visit, the researcher identified the breastfeeding practices that mothers learned at postpartum care facilities where most of the participants stayed after hospital discharge. Moreover, the researcher examined problems related to feeding with regard to the baby, the mother, and other factors during each home visit.

The Power Analysis and Sample Size (PASS) (NCSS, LLC, Kaysville, UT, USA) was used to estimate the proper sample size. The minimum required sample size was 36 for 4 repeated measurements with an $\alpha$ of $.05,80 \%$ power $(1-\beta)$, and 2 groups with breastfeeding rates of $55 \%$ (experimental group) and $25 \%$ (control group) [20]. A total of 41 LPIs were recruited after accounting for a possible dropout rate of $10 \%$. After 20 LPIs were recruited to be in the control group, another 21 LPIs were recruited to be in the experimental group. One of the control group participants refused a home visit in the first week after discharge and was removed from the study sample. Thus, there were ultimately 21 participants in the experimental group and 19 participants in the control group. The researchers regularly contacted the mothers of the LPIs via phone 
calls between home visits during the entire study period to prevent participants from dropping out. The study flow chart can be found in the previous study by Jang [19].

\section{Study Procedures}

The BCP was provided to the experimental group, which received breastfeeding education using web- and home-based practical lactation support as outlined by Jang [19]. Webbased breastfeeding education focused on the breastfeeding-related physical characteristics of LPIs, general guidelines for breastfeeding, and common breastfeeding challenges and solutions. The webpage controlled access so that only those in the experimental group could view the information. Homebased practical lactation support was provided to improve the mothers' one-on-one breastfeeding skills based on LPIs' physical maturation after assessing sucking power, suck-swallow-breathe coordination, and maternal confidence related to breastfeeding their LPIs. The 5-session program encouraged mothers to successfully transition from breast milk pumping to feeding at the breast.

The control group learned how to care for LPIs during weekly home visits. The experimental group was given the home visit and the web page where lactation education was available (http://momfeed.kr). LPIs are not physically mature enough to feed at the breast; therefore, the learning materials focused on pumping, various factors related to nursing LPIs, proper nursing methods, and the importance of pumping regularly. We provided practical tips and support for breastfeeding at weekly visits during which we also measured the weight, length, head circumference, and transcutaneous bilirubin (TcB) levels of the LPIs.

\section{Measurements}

The same researcher identified the feeding method by observing the dyad of LPIs and their mothers and measured the weight, length, head circumference, and TcB levels of LPIs in both groups to exclude the possibility of inter-observer error.

\section{1) Feeding method}

The feeding method was categorized as breastfeeding or formula-feeding and was identified at discharge and once a week for 4 weeks post-discharge. In this study, breastfeeding was defined as feeding directly from the breast or bottle-feeding pumped breast milk and small amounts of formula supplemented intermittently. Some LPIs' mothers supplemented with formula after breastfeeding when they perceived an inadequate supply of breast milk. If partial formula supplementation occurred once or twice a day, it was considered breastfeeding. Formula feeding was defined as feeding using formula only or not performing any breastfeeding.

\section{2) Growth}

Growth of LPIs was measured using body weight, weight gain, length, and head circumference during weekly home visits for 4 weeks post-discharge. Weight at discharge was confirmed by checking the hospital records as a baseline data point to assess weight gain. Weight and length were measured using a digital baby scale (SECA 334, Seca Deutschland, Hamburg, Germany). Head circumference was measured using a flexible metal tape measure, and the mean value of the two measurements was used as the head circumference.

\section{3) Neonatal jaundice}

Neonatal jaundice was defined based on the average of 3 measurements made on the forehead of the infants as suggested in previous studies [21,22] using a TcB meter (JM-103, Minolta/Hill-Rom Air-Shield, Osaka, Japan). TcB levels were assessed on the day of discharge day and once a week for 4 weeks after discharge.

\section{Data Collection}

Data collection took place at the NICU of a university-affiliated hospital in Daegu, South Korea, from June 2017 to May 2018. After data collection for the control group was completed from June to October 2017, data collection for the experimental group was conducted. A nurse who was a lactation specialist selected participants based on the inclusion and exclusion criteria, explained the purpose of the study to potential participants, and contacted the researcher after receiving consent from potential participants. The lactation specialist confirmed the demographic and clinical characteristics of the participants from their hospital records on the day before discharge, as well as the feeding method, body weight, and TcB level of the infants at discharge. In addition, the researcher assessed the feeding method and growth by measuring the infant's body weight, length, and head circumference as well as TcB levels to check neonatal jaundice at each visit from week 1 to 4 post-discharge. The researcher, an international board-certified lactation consultant, had significant experience conducting studies on breastfeeding and infant growth.

\section{Data Analysis}

Data were analyzed using SAS version 9.4 (SAS Institute Inc., Cary, NC, USA). First, homogeneity testing was conducted using descriptive statistics, the t-test, the $x^{2}$ test for the general and clinical characteristics, and the independent t-test 
for the study variables in the groups. Changes in feeding type in the groups were analyzed using generalized estimating equations (GEEs). Two-way repeated-measures analysis of variance (ANOVA) was performed to analyze body weight, length, and head circumference, and repeated-measures analysis of covariance (ANCOVA) was used to analyze the TcB levels of the infants over time.

\section{Ethical Considerations}

This study was conducted after receiving approval from the Daegu University Institutional Review Board (No. 1040621 -201505-HR-015-02). The participants were mothers of LPIs who voluntarily consented to participate in the study and signed an informed consent form.

\section{RESULTS}

\section{General and Clinical Characteristics of Participants}

No significant between-group differences were found in the general characteristics of the LPIs and their mothers (Table 1). There were no significant differences in sex, gestational age, birth order, number of babies, type of birth, body weight, Apgar score, use of a ventilator, use of phototherapy, or tube feeding for LPIs. The majority of the LPIs in both groups had a gestational age of 34 weeks and were delivered via cesarean section. The rate of ventilator use in the experimental group was higher than in the control group. The mean 1-minute and 5-minute Apgar scores were lower in the experimental group, at 6.81 and 8.33 , respectively, than in the control group, at 7.42 and 8.68 , respectively.

Table 1. General and Clinical Characteristics of Participants $(N=40)$

\begin{tabular}{|c|c|c|c|c|c|c|}
\hline \multirow{2}{*}{ Subjects } & \multirow{2}{*}{ Variables } & \multirow{2}{*}{ Categories } & Cont. $(n=19)$ & Exp. $(n=21)$ & \multirow{2}{*}{$x^{2}$ or $\mathrm{t}$} & \multirow{2}{*}{$p$} \\
\hline & & & $\mathrm{n}(\%)$ or $\mathrm{M} \pm \mathrm{SD}$ & $\mathrm{n}(\%)$ or $\mathrm{M} \pm \mathrm{SD}$ & & \\
\hline \multirow[t]{20}{*}{ Infant } & \multirow[t]{2}{*}{ Sex } & Male & $6(31.6)$ & $13(61.9)$ & \multirow[t]{2}{*}{3.68} & \multirow[t]{2}{*}{.055} \\
\hline & & Female & $13(68.4)$ & $8(38.1)$ & & \\
\hline & \multirow[t]{3}{*}{ Gestational age (week) } & 34 & $13(68.4)$ & $12(57.1)$ & \multirow[t]{3}{*}{1.03} & \multirow[t]{3}{*}{.596} \\
\hline & & 35 & $5(26.3)$ & $6(28.6)$ & & \\
\hline & & 36 & $1(5.3)$ & $3(14.3)$ & & \\
\hline & \multirow[t]{2}{*}{ Birth order } & First & $11(57.9)$ & $14(66.7)$ & \multirow[t]{2}{*}{0.33} & \multirow[t]{2}{*}{.567} \\
\hline & & Second & $8(42.1)$ & $7(33.3)$ & & \\
\hline & \multirow[t]{2}{*}{ Number of babies } & Singleton & $9(47.4)$ & $13(61.9)$ & \multirow[t]{2}{*}{0.85} & \multirow[t]{2}{*}{.356} \\
\hline & & Twin & $10(52.6)$ & $8(38.1)$ & & \\
\hline & \multirow[t]{2}{*}{ Type of birth } & NSVD & $3(15.8)$ & $4(19.0)$ & \multirow[t]{2}{*}{0.07} & \multirow[t]{2}{*}{.787} \\
\hline & & C-sec & $16(84.2)$ & $17(81.0)$ & & \\
\hline & Birth weight (g) & & $2,296 \pm 389$ & $2,156 \pm 280$ & 1.31 & .197 \\
\hline & \multirow[t]{2}{*}{ Apgar score } & 1-minute & $7.42 \pm 0.90$ & $6.81 \pm 1.36$ & 1.65 & .107 \\
\hline & & 5-minute & $8.68 \pm 0.58$ & $8.33 \pm 0.91$ & 1.43 & .160 \\
\hline & \multirow[t]{2}{*}{ Ventilator } & No & $10(52.6)$ & $9(42.9)$ & \multirow[t]{2}{*}{0.38} & \multirow[t]{2}{*}{.537} \\
\hline & & Yes & $9(47.4)$ & $12(57.1)$ & & \\
\hline & \multirow[t]{2}{*}{ Phototherapy } & No & $15(79.0)$ & $11(52.4)$ & \multirow[t]{2}{*}{3.09} & \multirow[t]{2}{*}{.079} \\
\hline & & Yes & $4(21.0)$ & $10(47.6)$ & & \\
\hline & \multirow[t]{2}{*}{ Tube feeding } & No & $8(42.1)$ & $7(33.3)$ & \multirow[t]{2}{*}{0.33} & \multirow[t]{2}{*}{.567} \\
\hline & & Yes & $11(57.9)$ & $14(66.7)$ & & \\
\hline \multirow[t]{5}{*}{ Mother } & Age (year) & & $34.0 \pm 3.1$ & $33.3 \pm 4.2$ & 0.61 & .546 \\
\hline & Employed & No & $13(68.4)$ & $11(52.4)$ & 1.07 & .301 \\
\hline & & Yes & $6(31.6)$ & $10(47.6)$ & & \\
\hline & Obstetric disease & No & $17(89.5)$ & $16(76.2)$ & 1.22 & .270 \\
\hline & & Yes & $2(10.5)$ & $5(23.8)$ & & \\
\hline
\end{tabular}

Cont., control group; C-sec, cesarean section; Exp., experimental group; NSVD, normal spontaneous vaginal delivery. 
Table 2. Comparison of Feeding Methods between the Groups Over Time $(N=40)$

\begin{tabular}{|c|c|c|c|c|c|c|c|c|c|c|c|c|}
\hline \multirow{2}{*}{ Time } & \multirow{2}{*}{ Categories } & \multicolumn{4}{|c|}{ Cont. ${ }^{*}(\mathrm{n}=19)$} & \multicolumn{4}{|c|}{ Exp.* $(n=21)$} & \multicolumn{3}{|c|}{ 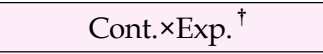 } \\
\hline & & n (\%) & OR & $95 \% \mathrm{CI}$ & $\mathrm{z}(p)$ & $\mathrm{n}(\%)$ & OR & $95 \% \mathrm{CI}$ & $\mathrm{z}(p)$ & OR & $95 \% \mathrm{CI}$ & $\mathrm{z}(p)$ \\
\hline \multirow[t]{2}{*}{ Discharge } & Breastfeeding & $13(68.4)$ & \multirow[t]{2}{*}{1} & & & $13(61.9)$ & \multirow[t]{2}{*}{1} & & & \multirow[t]{2}{*}{1} & & \\
\hline & Formula & $6(31.6)$ & & & & $8(38.1)$ & & & & & & \\
\hline \multirow[t]{2}{*}{ First week } & Breastfeeding & $13(68.4)$ & \multirow[t]{2}{*}{1.00} & \multirow[t]{2}{*}{ - } & \multirow[t]{2}{*}{ - } & $14(66.7)$ & \multirow[t]{2}{*}{1.23} & \multirow[t]{2}{*}{$0.61-2.48$} & 0.58 & \multirow[t]{2}{*}{1.23} & \multirow[t]{2}{*}{$0.61-2.48$} & 0.58 \\
\hline & Formula & $6(31.6)$ & & & & 7 (33.3) & & & $(.561)$ & & & $(.561)$ \\
\hline \multirow[t]{2}{*}{ Second week } & Breastfeeding & $11(57.9)$ & \multirow[t]{2}{*}{0.63} & \multirow[t]{2}{*}{$0.35-1.16$} & -1.48 & $12(57.1)$ & \multirow[t]{2}{*}{0.82} & \multirow[t]{2}{*}{$0.42-1.60$} & -0.58 & \multirow[t]{2}{*}{1.29} & \multirow[t]{2}{*}{$0.53-3.17$} & 0.56 \\
\hline & Formula & $8(42.1)$ & & & $(.138)$ & $9(42.9)$ & & & $(.561)$ & & & $(.575)$ \\
\hline \multirow[t]{2}{*}{ Third week } & Breastfeeding & $8(42.1)$ & \multirow[t]{2}{*}{0.34} & \multirow[t]{2}{*}{$0.14-0.80$} & -2.48 & $12(57.1)$ & \multirow[t]{2}{*}{0.82} & \multirow[t]{2}{*}{$0.29-2.28$} & -0.38 & \multirow[t]{2}{*}{2.44} & \multirow[t]{2}{*}{$0.64-9.33$} & 1.31 \\
\hline & Formula & $11(57.9)$ & & & $(.013)$ & $9(42.9)$ & & & $(.705)$ & & & (.191) \\
\hline \multirow[t]{2}{*}{ Fourth week } & Breastfeeding & $7(36.8)$ & \multirow[t]{2}{*}{0.27} & \multirow[t]{2}{*}{$0.11-0.68$} & -2.76 & $13(61.9)$ & \multirow[t]{2}{*}{1.00} & \multirow[t]{2}{*}{$0.38-2.64$} & 0.00 & \multirow[t]{2}{*}{3.71} & $0.97-14.25$ & 1.91 \\
\hline & Formula & $12(63.2)$ & & & $(.006)$ & $8(38.1)$ & & & $(>.999)$ & & & $(.056)$ \\
\hline
\end{tabular}

${ }^{*}$ Time effects using generalized estimating equations (GEEs) for each group; ${ }^{\dagger}$ Interaction effect between treatment (Cont. and Exp.) and time using a GEEs; CI, confidence interval; Cont., control group; Exp., experimental group; OR, odds ratio.

There were no significant differences in age, occupation, and obstetric disease status for the mothers. The average age of the mothers was 33 to 34 years old. More than two-thirds of the mothers in both groups had no obstetric diseases.

\section{Comparison of the Feeding Method}

In a comparison of the two groups over time using GEE, the breastfeeding rate in the experimental group remained consistent at $61.9 \%$ up to 4 weeks, whereas the rate dropped in the control group from $68.4 \%$ at discharge to $36.8 \%$ at the fourth week. A significant decrease in the breastfeeding rate was observed in the control group, with an odds ratio for breastfeeding of $0.34(\mathrm{z}=-2.48, p=.013)$ at week 3 and $0.27(\mathrm{z}=-2.76, p=$ .006 ) at week 4 , whereas no significant changes were observed in the experimental group. The interaction effect between the groups had an odds ratio of 3.71 for the fourth week, but it was not statistically significant $(\mathrm{z}=1.91, p=.056)$ (Table 2$)$.

\section{Comparisons of Growth and Neonatal Jaundice}

The body weight of LPIs showed a significant difference between the groups over time $(\mathrm{F}=5.69, p=.011)$ and over time $(\mathrm{F}=363.38, p<.001)$, but not between the groups $(\mathrm{F}=2.11$, $p=.154)$. Body length was significantly different between the groups over time $(\mathrm{F}=18.78, p<.001)$ and over time $(\mathrm{F}=373.33$, $p<.001)$, but not between the groups $(\mathrm{F}=3.69, p=.062)$. Head circumference presented a significant difference between the groups over time ( $\mathrm{F}=4.81, p=.003)$, over time $(\mathrm{F}=210.71, p<$ $.001)$, and between the groups $(\mathrm{F}=6.25, p=.017)$. Finally, the TcB levels of the infants showed no significant differences between the groups over time $(\mathrm{F}=1.03, p=.384)$, between the groups $(\mathrm{F}=0.06, p=.803)$, or over time alone $(\mathrm{F}=1.14, p=.337)$.
Repeated-measures ANCOVA, in which TcB levels at the time of discharge were used as a covariate since there was a statistically significant difference between the groups at baseline $(\mathrm{t}=2.30, p=.027)$, showed that the TcB levels were significantly different over time by the time of discharge $(\mathrm{F}=3.38, p=.036)$ (Table 3).

\section{DISCUSSION}

This study was conducted to identify the effects of a web-based BCP on LPIs treated in the NICU in which weekly home-based lactation support was provided for 4 weeks after discharge. The results showed that the breastfeeding rate and the growth of infants in the experimental group were higher than they were in the control group. However, the TcB levels of the experimental group, which had a higher breastfeeding rate, were not significantly different from those of the control group, which had a higher formula feeding rate.

First, the experimental group had a higher likelihood of being breastfed than those in the control group. The results of this study correspond to those of a study by Wataker et al. [23], in which the mothers of 36 LPIs who participated in a family care program were found to be significantly more likely to continue breastfeeding until 3 months postpartum than the mothers of LPIs in the control group $(n=30)$ who received traditional care in the NICU. Our results also align with those of a study by Jang and Ju [24], in which the breastfeeding rate (73.1\%) of mothers of LPIs who attended an Infant Care Education Program $(n=26)$ was higher than that of the control group $(40.7 \%)$ who did not attend the program $(n=27)$. An integrated review of 13 breastfeeding intervention studies [3] found that most interventions for LPIs helped to encourage exclusive breastfeeding and concluded that interventions that take place after LPIs 
Table 3. Comparison of Growth and Transcutaneous Bilirubin Levels between the Groups Over Time $(N=40)$

\begin{tabular}{|c|c|c|c|c|c|c|c|c|}
\hline \multirow{2}{*}{ Variables } & \multirow{2}{*}{ Time } & Cont. $(n=19)$ & Exp. $(n=21)$ & \multirow{2}{*}{$\mathrm{t}$} & \multirow{2}{*}{$p$} & \multirow{2}{*}{ Source } & \multirow{2}{*}{$\mathrm{F}$} & \multirow{2}{*}{$p$} \\
\hline & & $\mathrm{M} \pm \mathrm{SD}$ & $\mathrm{M} \pm \mathrm{SD}$ & & & & & \\
\hline \multirow[t]{5}{*}{ Body weight (g) } & Discharge & $2,258 \pm 374$ & $2,239 \pm 271$ & 1.16 & .256 & Group & 2.11 & .154 \\
\hline & First week & $2,528 \pm 343$ & $2,640 \pm 346$ & 0.28 & .778 & Time & 363.38 & $<.001$ \\
\hline & Second week & $2,842 \pm 317$ & $3,004 \pm 384$ & 1.07 & .289 & $\mathrm{G}^{*} \mathrm{~T}$ & 5.69 & .011 \\
\hline & Third week & $3,181 \pm 415$ & $3,391 \pm 427$ & 1.60 & .119 & & & \\
\hline & Fourth week & $3,483 \pm 576$ & $3,847 \pm 441$ & 2.36 & .024 & & & \\
\hline \multirow{4}{*}{ Length $(\mathrm{cm})$} & First week & $47.9 \pm 1.2$ & $48.3 \pm 1.7$ & 1.15 & .258 & Group & 3.69 & .062 \\
\hline & Second week & $48.8 \pm 1.4$ & $49.4 \pm 1.5$ & 1.35 & .184 & Time & 377.33 & $<.001$ \\
\hline & Third week & $49.4 \pm 1.4$ & $50.5 \pm 1.6$ & 2.50 & .017 & $\mathrm{G}^{* \mathrm{~T}}$ & 18.78 & $<.001$ \\
\hline & Fourth week & $50.0 \pm 1.5$ & $51.4 \pm 1.5$ & 3.70 & .001 & & & \\
\hline \multirow[t]{4}{*}{ Head circumference $(\mathrm{cm})$} & First week & $33.1 \pm 0.8$ & $33.5 \pm 0.8$ & 0.74 & .465 & Group & 6.25 & .017 \\
\hline & Second week & $33.8 \pm 0.8$ & $34.3 \pm 0.9$ & 1.57 & .125 & Time & 210.71 & $<.001$ \\
\hline & Third week & $34.3 \pm 0.9$ & $35.0 \pm 0.8$ & 2.36 & .024 & $\mathrm{G}^{*} \mathrm{~T}$ & 4.81 & .003 \\
\hline & Fourth week & $34.8 \pm 0.8$ & $35.8 \pm 0.9$ & 4.04 & $<.001$ & & & \\
\hline \multirow[t]{5}{*}{$\mathrm{TcB}(\mathrm{mg} / \mathrm{dL})$} & Discharge & $8.82 \pm 3.38$ & $6.11 \pm 3.07$ & 2.30 & .027 & Group & 0.06 & .803 \\
\hline & First week & $6.02 \pm 4.04$ & $3.98 \pm 2.50$ & 2.78 & .009 & Discharge & 11.26 & .002 \\
\hline & Second week & $4.38 \pm 3.31$ & $3.22 \pm 2.71$ & 2.27 & .029 & Time & 1.14 & .337 \\
\hline & Third week & $3.95 \pm 3.19$ & $2.71 \pm 2.81$ & 2.44 & .019 & $\mathrm{G}^{*} \mathrm{~T}$ & 1.03 & .384 \\
\hline & Fourth week & $3.44 \pm 2.96$ & $2.28 \pm 2.36$ & 2.47 & .018 & $\mathrm{D}^{*} \mathrm{~T}$ & 3.38 & .036 \\
\hline
\end{tabular}

Cont., control group; D, discharge; Exp., experimental group; G, group; T, time; TcB, transcutaneous bilirubin.

transition to living at home are needed. In addition, our study highlighted the effect of home-based lactation support for a certain portion of the postpartum period. These conclusions highlight the need for nursing interventions that provide education and support for mothers of LPIs to promote breastfeeding during the first several weeks after birth, which is critical for establishing longer-term breastfeeding.

Head circumference in the experimental group increased significantly faster than in the control group when comparing the effects of the BCP on infant growth; however, no significant changes were observed in the weight and length of LPIs between the groups. Thus, our results were similar to those of a previous study [24], which found that the weight, length, and head circumference of infants in the experimental group $(n=26)$, whose mothers attended an infant care education program, were not significantly different from those of the control group $(n=27)$. This is a similar finding to a study by Jang and Hong [20] that observed no significant differences in weight gain between the experimental group $(n=20)$, the participants of which attended a BCP, and the control group $(\mathrm{n}=$ 20). Our results also correspond to the findings of a meta-analysis of the effects of breastfeeding promotion interventions on infant growth that observed no significant differences in body weight and length [18]. The mean body weight in the experimental group, however, was significantly higher than that in the control group at the fourth week $(\mathrm{t}=2.36, p=.024)$, and the mean body length was also higher at the third $(\mathrm{t}=2.50, p=.017)$ and fourth week $(\mathrm{t}=3.70, p=.001)$. The BCP provided in this study focused on breastfeeding support by reassuring mothers of the appropriate feeding amount and boosting their confidence to continue breastfeeding, which could explain why growth in the control group in this study also remained consistent. A study by Kent et al. [25] found that measuring infants' weight before and after feeding helped mothers to remain determined to continue breastfeeding, taking into account the difficulty of verifying the total intake amount. Therefore, further studies are needed that extend the intervention period to compare the growth of infants.

Lastly, our comparison of the effects of the BCP on neonatal jaundice among LPIs found that TcB levels were not significantly different between groups, although the levels decreased naturally over time. This finding contrasts with those of previous studies $[12,13,26]$ that found breastfeeding to be a risk factor for neonatal jaundice, while it supports the findings of other studies that found insufficient milk intake to be the cause of elevated TcB levels, rather than breast milk itself $[8,14]$. Furthermore, the body weight of LPIs at the fourth week in the experimental group was higher than in the control group, which suggests that the LPIs in the experimental group were able to consume an appropriate amount of breast milk and that their TcB levels declined at a similar rate to those in the control group, which had a higher rate of formula feeding. This result corresponds to the results of a study by Park et al. [14] on 79 Korean infants born at 35 gestational weeks or later who were hospitalized in a NICU approximately 8 days after birth with idiopathic nonhemolytic hyperbilirubinemia. Their 
study found that serum bilirubin levels were higher in infants with a more considerable weight drop than in infants who showed weight loss at hospitalization compared to their birth weight $(n=55)$ and infants who gained weight $(n=24)$.

Breastfeeding promotion interventions are most effective when mothers continue to apply lactation education they received in hospitals after they return to their communities [27]. However, most breastfeeding interventions are conducted in the hospital only and are often discontinued upon the mother and infant's discharge. In this study, the intervention continued up to 4 weeks after hospital discharge. In other words, the $\mathrm{BCP}$ provided in this study was successfully reinforced by extending postnatal education from a specialist nurse at the hospital to the home. The BCP also showed positive results by providing tailored education for each LPI based on assessments of the infant's maturity and growth, the mother's health, and feeding issues following web education and practical support.

Despite the positive results of the $\mathrm{BCP}$, there were some limitations to this study. First, the BCP was provided and the variables were measured by the same researcher, who was aware of the sample allocation of the groups. Therefore, potential bias in the results cannot be entirely ruled out. However, the feeding method was identified through observation, and growth and jaundice were measured mechanically to minimize potential bias. Second, formula feeding partially supplemented with breastfeeding was included in the breastfeeding rate, so the effects of the BCP on exclusive breastfeeding were not confirmed. In Korea, most LPIs are supplemented with formula for several weeks after discharge to promote growth, meaning that the effects of exclusive breastfeeding could not be studied. Therefore, the exclusive breastfeeding rate should be examined in future studies over a longer study period. Third, the results have somewhat limited generalizability due to the small sample size from one hospital in a single city, and further studies are thus recommended. Lastly, since maternal factors influencing the commencement of breastfeeding were not included in this study, further studies are recommended to supplement the present study.

\section{CONCLUSION}

This study was conducted to identify the effects of a webbased BCP for LPIs and showed positive effects on the improvement of breastfeeding. This finding was a consequence of the $\mathrm{BCP}$ being an ongoing community-based program that provided breastfeeding support based on the physical maturation and health conditions of LPIs rather than a one-time hospital-based intervention. Therefore, a BCP like the one in the present study should be conducted in the future for the mothers of LPIs.

\section{ORCID}

Gun Ja Jang

https://orcid.org/0000-0002-1028-8066

Sangjin Ko

\section{Authors' contribution}

Conceptualization: Gun Ja Jang; Data collection: Gun Ja Jang; Formal analysis: Sangjin Ko; Writing-original draft, Writingreview and editing: all authors; Final approval of published version: all authors.

\section{Conflict of interest}

No existing or potential conflict of interest relevant to this article was reported.

\section{Funding}

None.

\section{Data availability}

Please contact the corresponding author for data availability.

\section{Acknowledgements}

Special thanks to Ms. Seo-yoon Kim, a lactation specialist nurse in the NICU, for obtaining the consent of participants and connecting the participants with the researcher.

\section{REFERENCES}

1. Korean Statistical Information Service. Birth statistics 2010 [Internet]. Daejeon: Statistics Korea; 2010 [cited 2021 September 20]. Available from:

http://kostat.go.kr/portal/korea/kor_nw/1/2/1/index.board? bmode=read\&aSeq $=249892$

2. Korean Statistical Information Service. Birth statistics 2020 [Internet]. Daejeon: Statistics Korea; 2021 [cited 2021 September 20]. Available from:

http://kostat.go.kr/portal/korea/kor_nw/1/1/index.board?bm ode $=$ read\&aSeq $=391575$

3. Cartwright J, Atz T, Newman S, Mueller M, Demirci JR. Integrative review of interventions to promote breastfeeding in the late preterm infant. Journal of Obstetric, Gynecologic, and Neonatal Nursing. 2017;46(3): 347-356.

https://doi.org/10.1016/j.jogn.2017.01.006

4. Cooper BM, Holditch-Davis D, Verklan MT, Fraser-Askin D, Lamp J, Santa-Donato A, et al. Newborn clinical outcomes of the 
AWHONN late preterm infant research-based practice project. Journal of Obstetric, Gynecologic, and Neonatal Nursing. 2012;41 (6):774-785. https://doi.org/10.1111/j.1552-6909.2012.01401.x

5. UNICEF KOREA. Baby friendly hospital [Internet]. Seoul: The Korean Committee for Unicef; [cited 2021 August 5]. Available from: https://www.unicef.or.kr/child-rights/initiative/baby-friendlyhospital.asp

6. Hallowell SG, Spatz DL. The relationship of brain development and breastfeeding in the late-preterm infant. Journal of Pediatric Nursing. 2012;27(2):154-162.

https://doi.org/10.1016/j.pedn.2010.12.018

7. Hackman NM, Alligood-Percoco N, Martin A, Zhu J, Kjerulff KH. Reduced breastfeeding rates in firstborn late preterm and early term infants. Breastfeeding Medicine. 2016;11(3):119-125. https://doi.org/10.1089/bfm.2015.0122

8. Wells C, Ahmed A, Musser A. Strategies for neonatal hyperbilirubinemia: A literature review. American Journal of Maternal Child Nursing. 2013;38(6):377-382.

https://doi.org/10.1097/NMC.0b013e3182a1fb7a

9. Soldi A, Tonetto P, Varalda A, Bertino E. Neonatal jaundice and human milk. Journal of Maternal-Fetal and Neonatal Medicine. 2011;24(1):85-87. https://doi.org/10.3109/14767058.2011.607612

10. Academy of Breastfeeding Medicine. ABM clinical protocol \#10: Breastfeeding the late preterm infant $\left(34^{0 / 7}\right.$ to $36^{6 / 7}$ weeks gestation) (first revision june 2011). Breastfeeding Medicine. 2011; 6(3):151-156. https://doi.org/10.1089/bfm.2011.9990

11. Briere CE, Lucas R, McGrath JM, Lussier M, Brownell E. Establishing breastfeeding with the late preterm infant in the NICU. Journal of Obstetric, Gynecologic, and Neonatal Nursing. 2015;44(1): 102-113. https://doi.org/10.1111/1552-6909.12536

12. Chen CF, Hsu MC, Shen $\mathrm{CH}$, Wang CL, Chang SC, Wu KG, et al. Influence of breast-feeding on weight loss, jaundice, and waste elimination in neonates. Pediatrics and Neonatology. 2011;52(2): 85-92. https://doi.org/10.1016/j.pedneo.2011.02.010

13. McGillivray A, Polverino J, Badawi N, Evans N. Prospective surveillance of extreme neonatal hyperbilirubinemia in Australia. Journal of Pediatrics. 2016;168:82-87.

https://doi.org/10.1016/j.jpeds.2015.08.048

14. Park S, Kang J, Kwon S, Kim H, Kim Y. The clinical characteristics according to the risk factors of idiopathic nonhemolytic hyperbilirubinemia. Journal of the Korean Society of Neonatology. 2013; 17(2):224-231. https://doi.org/10.5385/jksn.2010.17.2.224

15. Waite WM, Taylor JA. Phototherapy for the treatment of neonatal jaundice and breastfeeding duration and exclusivity. Breastfeeding Medicine. 2016;11(4):180-185.

https://doi.org/10.1089/bfm.2015.0170

16. De Onis M, Blössner M. The world health organization global database on child growth and malnutrition: Methodology and applications. International Journal of Epidemiology. 2003;32(4):518-526. https://doi.org/10.1093/ije/dyg099

17. Villar J, Giuliani F, Barros F, Roggero P, Zarco IA, Rego MA, et al. Monitoring the postnatal growth of preterm infants: A paradigm change. Pediatrics. 2018;141(2):e20172467.

https://doi.org/10.1542/peds.2017-2467

18. Giugliani ER, Horta BL, de Mola CL, Lisboa BO, Victora CG. Effect of breastfeeding promotion interventions on child growth: A systematic review and meta-analysis. Acta Paediatrica. 2015;104(467): 20-29. https://doi.org/10.1111/apa.13160

19. Jang GJ. Influence of a breastfeeding coaching program on the breastfeeding rates and neonatal morbidity in late preterm infants. Child Health Nursing Research. 2020;26(3):376-384.

https://doi.org/10.4094/chnr.2020.26.3.376

20. Jang GJ, Hong YR. Effects of a breastfeeding support program on the prevalence of exclusive breastfeeding and growth in late preterm infants. Child Health Nursing Research. 2020;26(1):90-97. https://doi.org/10.4094/chnr.2020.26.1.90

21. Akahira-Azuma M, Yonemoto N, Mori R, Hosokawa S, Matsushita $\mathrm{T}$, Sukhbat K, et al. An hour-specific transcutaneous bilirubin nomogram for Mongolian neonates. European Journal of Pediatrics. 2015;174(10):1299-1304.

https://doi.org/10.1007/s00431-015-2536-2

22. Romagnoli C, Tiberi E, Barone G, Curtis MD, Regoli D, Paolillo P, et al. Validation of transcutaneous bilirubin nomogram in identifying neonates not at risk of hyperbilirubinaemi: A prospective, observational, multicenter study. Early Human Development. 2012; 88(1):51-55. https://doi.org/10.1016/j.earlhumdev.2011.07.001

23. Wataker H, Meberg A, Nestaas E. Neonatal family care for 24 hours per day: Effects on maternal confidence and breast-feeding. Journal of Perinatal and Neonatal Nursing. 2012;26(4):336-342. https://doi.org/10.1097/JPN.0b013e31826d928b

24. Jang EH, Ju HO. Effects of an infant care education program for mothers of late-preterm infants on parenting confidence, breastfeeding rates, and infants' growth and readmission rates. Child Health Nursing Research. 2020;26(1):11-22. https://doi.org/10.4094/chnr.2020.26.1.11

25. Kent JC, Hepworth AR, Langton DB, Hartmann PE. Impact of measuring milk production by test weighing on breastfeeding confidence in mothers of term infants. Breastfeeding Medicine. 2015;10(6):318-325. https://doi.org/10.1089/bfm.2015.0025

26. Maisels MJ, Clune S, Coleman K, Gendelman B, Kendall A, McManus $\mathrm{S}$, et al. The natural history of jaundice in predominantly breastfed infants. Pediatrics. 2014;134(2):e340-e345. https://doi.org/10.1542/peds.2013-4299

27. Kim SK, Park S, Oh J, Kim J, Ahn S. Interventions promoting exclusive breastfeeding up to six months after birth: A systematic review and meta-analysis of randomized controlled trials. International Journal of Nursing Studies. 2018;80:94-105.

https://doi.org/10.1016/j.ijnurstu.2018.01.004 